\title{
Cartografia: uma outra forma de pesquisar
}

\section{Resumo}

Este artigo apresenta pistas introdutórias acerca do uso da cartografia no universo de uma pesquisa. Pensa a cartografia enquanto um outro modo ou maneira de pesquisar. Problematiza o fato de ser uma prática singular e suja de pesquisa, com ênfase no processo e não em objetivos a priori. Ao entender a cartografia enquanto criação de mundos, conclui que todo cartógrafo é um artista.

Palavras-chave: cartografia, pesquisa, metodologia

\section{Cartography: another possibility to research}

\begin{abstract}
This paper presents introductory clues about the use of cartography in the universe of research. Think cartography while another mode or way to search. It discusses the fact that it is a singular and dirty research practice, with an emphasis on the process rather than on objective a priori. By understanding the cartography while creating worlds, concludes that each cartographer is an artist.
\end{abstract}

Keywords: cartography, research, methodology

Pela primeira vez, uma perna quer sair por

minha boca, espremida. Um braço quer sair por

minha boca. E o que ainda há de genitália, e o que ainda há de intestino, e o que ainda... Quer sair por minha boca. Uma parede, uma hélice, um vidro de janela querem sair por minha boca. Um carro acelerado, um pedaço de mar, um fuzil. Sob o testemunho pânico de alguns, uma desordem no corpo e nas coisas, uma fronteira desguarnecida 
entre a pessoa e a cidade.

Alberto Pucheu, A fronteira desguarnecida, 2007

Logo de imediato, o leitor perceberá que este texto se faz ao modo primeiros passos. De forma introdutória, destina-se ao leitor interessado na cartografia enquanto prática de pesquisa, oferecendo provocações iniciais acerca do tema. Em minha trajetória enquanto pesquisador e orientador de pesquisa, constantemente deparo-me com processos investigativos que requerem metodologias inventivas. Muitas vezes senti a necessidade de oferecer um texto que pudesse ser uma porta de entrada a quem pretende se aventurar pelo exercício cartográfico, um texto-convite ou algo do gênero. Esta é a intenção na construção deste material, uma porta que certamente levará a ambientes mais complexos e densos caso a temática seja efetivamente assumida.

De um modo geral, mais do que uma metodologia científica, a cartografia aqui é entendida enquanto uma prática ou pragmática de pesquisa. A ideia de pragmática está ligada a um exercício ativo de operação sobre o mundo, não somente de verificação, levantamento ou interpretação de dados. O cartógrafo, aqui assumido enquanto pesquisador, atua diretamente sobre a matéria a ser cartografada. No entanto, ele nunca sabe de antemão os efeitos e itinerários a serem percorridos. Na força dos encontros gerados, nas dobras produzidas na medida em que habita e percorre os territórios, é que sua pesquisa ganha corpo. O corpo, aliás, é uma importante imagem no exercício de uma cartografia, corpo que nos remete ao corpo do pesquisador e ao corpo dos encontros estabelecidos.

Os fragmentos abaixo procuram, de certa forma, criar um corpo inicial e provisório à prática da cartografia na pesquisa, independentemente da área de saber envolvida. Sobre isto, o leitor será logo advertido, de que os saberes exclusivos de cada área são sempre insuficientes quando se procura cartografar territórios. Como o que se passa entre é o mais interessante, resta ao cartógrafo estar suficientemente poroso a estas microssensibilidades que se instauram nas zonas fronteiriças. Aliás, por tornar mais desguarnecidas as fronteiras que uma cartografia é efetivamente traçada. Do contrário, segue-se o que tradicionalmente chamamos de dados, resultados e conclusões, com os quais o mundo e a vida parecem nunca se adequar. 


\section{De início, uma conversa}

- O que é cartografia?

- É uma ciência geográfica que produz e estuda mapas.

- Mas mapas de quê?

- De territórios, ora bolas.

- De territórios?

- Sim. De países, cidades, regiões, estados...

- Mas o que esse papo de geografia tem a ver com o que estou pesquisando?

- Ora, até onde eu saiba, toda pesquisa trabalha com territórios.

- Territórios? Hum, não entendi...

- Sim, territórios. Podemos falar em territórios subjetivos, territórios afetivos, territórios estéticos, territórios políticos, territórios existenciais, territórios desejantes, territórios morais, territórios sociais, territórios históricos, territórios éticos e assim por diante.

- Hum...

- Cada saber lida com matérias que não são nada estanques, paradas, e que se caracterizam exclusivamente por serem relacionais, por estabelecerem relações entre si e com o seu meio.

- E que matérias seriam estas?

- Trata-se da vida, da subjetividade, de algo que é ao mesmo tempo singular e coletivo, que se faz entre o que é mais íntimo e aquilo que está fora, algo que está sempre em movimento, que nunca é exatamente uma coisa porque está sempre entre.

- Acho que estou entendendo, embora esteja com uma pulga atrás da orelha...

- Mostre-me qual seria a pulga, então.

- A questão que ficou para mim, o que não consegui ainda entender, é como mapear ou cartografar algo que nunca para?

- Fale mais... 
- Como posso fazer um mapa de algo que sempre está entre, que não é exatamente uma coisa ou outra, que está sempre em mutação?

- Agora é você que me confunde. Dê um exemplo para ficar mais claro.

- Um fotógrafo, por exemplo, para que possa fazer um retrato $3 X 4$, precisa que o outro pose em sua frente, de preferência o mais parado possível...

- Aí que está a diferença. A cartografia não é uma fotografia 3X4, não é um retrato de algo, uma descrição de alguma coisa que já está pronta de antemão, pronta para ser mapeada ou fotografada.

- Agora complicou...

- Ora, é preciso que o próprio cartógrafo esteja em movimento, afetando e sendo afetado por aquilo que cartografa. O cartógrafo cartografa sempre o processo, nunca o fim. Até porque o fim nunca é na realidade o fim. O que chamamos de final é sempre um fim para algo que continua de uma outra forma. Se não conseguimos enxergar movimento é porque alguma coisa está impedindo, e lançar o olhar para isto é também função do cartógrafo. A cartografia é, desde o começo, puro movimento e variação contínua.

- Parece que estou entendendo, mas ainda não consigo ver como uma cartografia funciona na prática.

- Veja bem... Para cartografar é preciso, além de um saber específico, algo que é fundamental, sem o qual não há possibilidade nenhuma de cartografia.

- Estou curioso... Que coisa seria esta?

- Para cartografar é preciso estar num território.

\section{Acompanhar processos}

A cartografia, da forma como aqui compreendemos, foi formulada pelos filósofos franceses Gilles Deleuze e Félix Guattari. Em uma varredura nos cinco volumes que compõem a edição brasileira de Mil Platôs: capitalismo e esquizofrenia, publicado pelos autores em 1980, percebemos o quanto a cartografia - também chamada de esquizoanálise, pragmática e micropolítica - pode se apresentar enquanto uma prática singular de pesquisa e de análise. O conceito, inicialmente retirado da geografia, é transposto para os campos da filosofia, política e subjetividade. O que os filósofos 
querem é pensar a realidade através de outros dispositivos que não os apresentados tradicionalmente pelos discursos científicos, valorizando aquilo que se passa nos intervalos e interstícios, entendendo-os como potencialmente formados e criadores de realidade. Sobre isto, Boaventura dos Santos (2002, p. 48) nos adverte: “cada método é uma linguagem, e a realidade responde na língua em que foi perguntada". Se formos entender a cartografia enquanto metodologia, precisamos pensar nas perguntas que ela pode nos ajudar a oferecer. Ao invés de perguntar pela essência das coisas, o cartógrafo pergunta pelo seu encontro com as coisas durante sua pesquisa. No lugar de o que é isto que vejo? (pergunta que remete ao mundo das essências), um como eu estou compondo com isto que vejo? Este segundo tipo de pergunta nos direciona ao processo, entendendo o cartógrafo enquanto criador de realidade, um compositor, aquele que com/põe na medida em que cartografa.

Complexidades à parte, o certo é que a cartografia surge como uma possibilidade de pesquisa que vem crescendo muito, uma prática investigativa que, ao invés de buscar um resultado ou conclusão, procura acompanhar o processo. É cada vez mais recorrente o uso da cartografia em projetos de pesquisa, em monografias de conclusão de curso, dissertações de mestrado e teses de doutorado. De toda forma, há uma rica gama de possibilidades em relação ao procedimento cartográfico; ele pode ser utilizado em toda e qualquer realidade onde o pesquisador queira acompanhar um processo.

\section{A reversão do método}

Se formos levar em conta a etimologia da palavra metodologia - metá-hódos, trata-se de um caminho (hódos) determinado pelas metas (metá) que são estabelecidas para que o próprio caminhar seja feito. De acordo com Passos, Kastrup (2009, p.11), “a cartografia propõe uma reversão metodológica: transformar o méta-hódos em hódos-metá". Segundo os autores, tal reversão se faz por uma aposta de experimentação do pensamento. Trata-se de um método que não será aplicado, mas experimentado e assumido enquanto uma atitude de pesquisa. “Com isso não se abre mão do rigor (...) $\mathrm{O}$ rigor do caminho, sua precisão, está mais próximo dos movimentos da vida (Ibidem, p. 11)". Desta forma, o que se percebe na cartografia é que o pesquisador-cartógrafo vai constituindo seus passos estando no próprio campo (lembre-se da última frase do diálogo que inicia este artigo, "de que para cartografar, é preciso estar no território". o pesquisador-cartógrafo não sabe, de antemão, o que irá lhe atravessar, quais serão os encontros que irá ter e no que estes mesmos encontros poderão acarretar. O cartógrafo, 
de certa forma, é um amante dos acasos, ele está disponível aos acasos que o seu campo lhe oferece, aos encontros imprevisíveis que se farão no decorrer do caminho.

\section{Modo de usar}

A cartografia não tem um único modo de utilização, não busca estabelecer regras ou caminhos lineares para que se atinja um fim. O pesquisador-cartógrafo terá que inventar os seus na medida em que estabelece relações e passa a fazer parte do seu próprio território de pesquisa.

\section{Uma prática de pesquisa suja}

O pesquisador-cartógrafo é também parte da geografia a qual se ocupa - não se pode, em uma pesquisa cartográfica, situar o campo de pesquisa como algo que estaria "lá" e o pesquisador "aqui". A cartografia, neste sentido, é uma prática de pesquisa suja, distante da assepsia e da limpeza que método científico positivista nos propõe. O cartógrafo, ao estar implicado no seu próprio procedimento de pesquisa, não consegue (e não deseja) manter-se neutro e distante - eis o sentido de sujeira aplicado à sua prática. Ele se mistura com o que pesquisa, e isto faz parte de sua cartografia. A cartografia se ocupa dos caminhos errantes, estando suscetível a contaminações e variações produzidas durante o próprio processo de pesquisa. A cartografia exige do pesquisador posturas singulares. Não coleta dados; ele os produz. Não julga; ele coloca em questão as forças que pedem julgamento. A cartografia ocupa-se de planos moventes, de campos que estão em contínuo movimento na medida em que o pesquisador se movimenta. Cartografar exige como condição primordial estar implicado no próprio movimento de pesquisa. A sujeira é essa mistura necessária.

\section{A multiplicação do mundo}

Diz-se que uma cartografia é uma pesquisa implicada e mutiplicante. No entanto, falamos de outra forma de implicação, um implicar-se menos subjetivo e mais ao sabor dos encontros. Em latim, plic ou plica nos remetem à ideia de prega, dobra. Neste sentido, implicar estaria voltado ao dobrar, à produção de uma dobra. O pesquisador implicado é o pesquisador dobrado pela sua pesquisa. No entanto, criador e sujo que é, o 
pesquisador também será um multiplicador, um disseminador de novas dobras ao que supostamente pesquisa. Ao invés de somente explicar, de desdobrar a dobra, seu olhar e escrita multi/implicam o mundo.

\title{
A cartografia é feita de encontros
}

Se pudéssemos apresentar um elemento fundamental para uma prática cartográfica, este seria o encontro. Entretanto é preciso superar a noção comum de encontro como um "encontrar algo" ou "achar alguém ou alguma coisa". O encontro, da forma como aqui falaremos, é da ordem do inusitado e nunca se faz sem um grau de violência (é claro que não estamos falando de uma violência física; mas de um movimento que é violento porque nos desacomoda e nos faz sair do mesmo lugar). Deleuze, em Diálogos (1998), fala do encontro como uma espécie de solidão extremamente povoada. É solitário (porque um encontro nos atravessa sempre de maneira única e singular) e povoado (porque um encontro se dá entre nós e alguma coisa). Um encontro é sempre ziguezagueante, algo que se passa entre dois, transitando pela multiplicidade de coisas e signos que povoam o momento singular do encontrar-se. No Abecedário de Gilles Deleuze (1988), na letra C de Cultura, o filósofo fala acerca do que entende por um verdadeiro encontro:

\begin{abstract}
Não acredito na cultura; acredito, de certo modo, em encontros. E não se têm encontros com pessoas. As pessoas acham que é com pessoas que se têm encontros. É terrível, isso faz parte da cultura, intelectuais que se encontram, essa sujeira de colóquios, essa infâmia, mas não se tem encontros com pessoas, e sim com coisas, com obras: encontro um quadro, encontro uma ária de música, uma música, assim entendo o que quer dizer um encontro. Quando as pessoas querem juntar a isso um encontro com elas próprias, com pessoas, não dá certo. Isso não é um encontro. Daí os encontros serem decepcionantes, é uma catástrofe os encontros com pessoas.
\end{abstract}

Neste sentido, tudo é passível de gerar um encontro cartográfico. As coisas aparentemente mais insignificantes e imprevisíveis podem ser extremamente potentes.

\section{I mportâncias}


Por se mostrar disponível às coisas que se apresentam no caminho (e não são poucas as coisas que nos entornam) é comum (e esperado) que o pesquisador-cartógrafo se veja constantemente exposto a dilemas do tipo: será que isto é importante para minha pesquisa? A condição para selecionar o que fará parte de sua pesquisa é a força do encontro gerado. Antes de se perguntar se determinada coisa é ou não importante, o cartógrafo procurará pensar se houve ou não encontro com esta coisa. No caso de haver, ele apostará no registro. No caso de não, ele poderá negligenciá-la. Para o cartógrafo, o grau de importância das coisas não está ligado à importância social, ao que se convenciona a priori enquanto importante. A importância é aquilo que se consegue levar/portar a partir de um encontro. Na pragmática de uma cartografia, a importância é antes uma portância.

\section{O cartógrafo gramado}

Para entender melhor a questão do entre, Deleuze, em Diálogos (1998), faz uma referência a um fragmento do escritor americano Henry Miller, no qual ele fala da força da grama. “(...) a grama só existe entre os grandes espaços não cultivados. Ela preenche os vazios. Ela brota entre as outras coisas. A flor é bela, o repolho útil, a tulipa endoidece. Mas a grama é transbordamento, é uma lição de moral". O cartógrafo, ao cartografar o que se passa nos intervalos, deve aprender muito com a grama. É no espaço não-cultivado das importâncias culturais e sociais que ele colocará seu olho e corpo. Ele perguntará por aquilo que brota nos espaços mais improváveis, pelos montículos de vida que se fazem nos cantos, naquilo que o próprio espaço costuma refugar ou avaliar enquanto não importante. Neste sentido, dizemos que o pesquisador é um gamado em grama e que sua cartografia não deixa de ser um desenho dos desdenhos sociais.

\section{Sensibilidade suspeita}

Uma cidade é feita de linguagens e de imagens. É composta por sensações fugidias que escapam aos nossos olhares, que não encontram na boca da gramática palavras que possam descrevê-las. Quais são as indagações que fazemos aos nossos territórios? A cartografia dirá que as nossas questões não vêm simplesmente das nossas cabeças, mas que nós nos questionamos na medida em que estabelecemos relações com aquilo que nos faz questionar. De outra forma, nós só nos indagamos sobre uma cidade na medida em que produzimos encontro com algo desta cidade. É preciso, então, que a gente entre 
em contato com as coisas para que as coisas nos façam pensar e sair do lugar. Sair do lugar não é simplesmente se deslocar; envolve outro tipo de deslocamento. Trata-se de um deslocamento das ideias prontas, daquilo que está naturalizado, do “é assim mesmo", do óbvio, sem surpresas, do que parece estar desde sempre já dado. Em outras palavras, trata-se de um deslocamento do olhar. O cartógrafo precisa necessariamente ter uma sensibilidade suspeita, precisa ter algo que, embora pareça muito comum, é cada vez mais raro: uma genuína curiosidade. Para isso, necessita estar disponível, uma boa dose de disponibilidade. Estar disponível é estar à espreita, com uma atenção leve. Não demasiadamente atento, o que o fará negligenciar todas as outras coisas que estão à sua volta; não demasiadamente distraído, o que tornaria a percepção muito volátil. É na medida certa do seu encontro que ele repousará sua atenção.

\section{É tudo manipulação}

De acordo com Kastrup (2009, p.30), “defender que toda pesquisa é intervenção exige do cartógrafo um mergulho no plano da experiência, lá onde conhecer e fazer se tornam inseparáveis, impedindo qualquer pretensão à neutralidade ou mesmo suposição de um sujeito e de um objeto cognoscentes prévios à relação que os liga". Neste sentido, conhecer uma coisa é também manipular esta coisa, emprestar à coisa o peso de nossas mãos e o timbre de nossas impressões digitais. Antes de um processo cognitivo, de apreensão mental, a manipulação nos faz pensar no resgate do corpo, da mão enquanto sensibilidade tátil no contato com as coisas e nas operações que faz a partir disso. Manipular é trazer para a mão o que outrora era de uma ordem mental. É por isso que dizemos que todo o "achado" cartográfico é, antes de tudo, pura manipulação.

\section{O corpo como razão}

“Há mais razão no teu corpo do que tua melhor sabedoria", afirma Nietzsche (1966, p. 43). O grande instrumento de razão de uma cartografia é o corpo. É preciso, pois, saber ouvi-lo e acioná-lo, afinal "o corpo é uma razão em ponto grande, uma multiplicidade com um só sentido, uma guerra e uma paz, um rebanho e um pastor" (Ibidem, p. 32). 0 fato de o cartógrafo ser um caminhante e um manipulador nos faz pensar na força de irrupção do corpo na pesquisa, no corpo físico do pesquisador e no corpo que cria com as coisas que encontra. Dizer que uma cartografia é uma prática corporal nos parece algo interessante. Trata-se de uma autoria do corpo, de traçados do corpo no encontro com o mundo, de trajetos corpo/autorais. 


\section{A queda bem-vinda}

A cartografia coloca em relação um conjunto de saberes: o cartógrafo pode ser um filósofo, sociólogo, um psicólogo, mas ele também terá de ser um historiador, um geógrafo, um sintomatologista, um clínico e, sobretudo, um artista. Ele trará para sua pesquisa estes múltiplos campos que se sobrepõem e que se atravessam no seu trabalho. O cartógrafo não é o grande olho de uma pesquisa, o sujeito que tudo olha com neutralidade, excessivamente confiante no seu saber exclusivo. O cartógrafo sabe que é impossível não se misturar e que esta mistura é justamente o que ele procura promover. Ele sabe que seu saber é tão vacilante quanto à realidade sobre a qual ele se ocupa. Ao invés de coletar verdades, o cartógrafo abre caminho para os fluxos, para aquilo que aponta para criação e que justamente resiste aos congelamentos. Ali onde a verdade gagueja, no pé vacilante da verdade, que ele pega carona. É por isso que dizemos que na cartografia a queda é muito bem-vinda. Afinal, só tropeçamos quando nosso pé se encontra com algo.

\section{A função do cartógrafo}

Dar passagem, fazer passagem, ser passagem.

\section{O que um cartógrafo precisa levar consigo}

- Suja, a cartografia nunca poderá ter como ideal a transparência e neutralidade;

- Segundo o mais conhecido fragmento de Heráclito, a gente nunca se banha duas vezes em um mesmo rio porque o rio nunca é o mesmo assim como a gente também não o é. No que diz respeito à cartografia diríamos que a gente nunca pisa duas vezes em um mesmo campo de pesquisa;

- Ao lidar com territórios que são moventes, cabe ao cartógrafo o exercício de uma sensibilidade plural. O saber do cartógrafo é sempre um saber multi/implicado, frágil e um tanto provisório;

- Inseparabilidade entre conhecer e fazer; pesquisar e intervir: toda cartografia é um conhecer-fazendo;

- Cartografar é estar, e não olhar de fora; 
- Só se faz cartografia artistando-se.

\section{Referências}

DELEUZE, G. PARNET, C. Diálogos. São Paulo: Escuta, 1998.

DELEUZE, Gilles; GUATTARI, Felix. Mil platôs: capitalismo e esquizofrenia. vol. 1 . São Paulo: Ed. 34, 1995a.

Mil platôs: capitalismo e esquizofrenia. vol. 2.São Paulo: Ed. 34, 1995b.

Mil platôs: capitalismo e esquizofrenia. vol. 3. São Paulo: Ed. 34, 1996.

Mil platôs: capitalismo e esquizofrenia. vol. 4. São Paulo: Ed. 34, 1997a.

Mil platôs: capitalismo e esquizofrenia. vol. 5. São Paulo: Ed. 34, 1997b.

DELeuZE, G. PARnet, C. O Abecedário de Gilles Deleuze. Entrevista em vídeo. França, 1988.

KASTRUP. Virginia. PASSOS, Eduardo. ESCÓSSIA, Liliana. Pistas do método da cartografia: pesquisa-intervenção e produção de subjetividade. Porto Alegre: Editora Sulina, 2009.

NIETZSCHE, Friedrich. Assim falava Zaratustra. Rio de Janeiro: Clássicos de Ouro, 1966.

PUCHEU, Alberto. A fronteira desguarnecida: poesia reunida 1993 - 2007. Rio de Janeiro: Beco do Azougue, 2007.

SANTOS, Boaventura dos. Um discurso sobre as ciências. Porto: Afrontamento, 2002. 
Luciano Bedin da Costa (UFRGS/RS)

Psicólogo, doutor em Educação e docente da Faculdade de Educação da Universidade Federal do Rio Grande do Sul. Pesquisa a relação entre escritura e vida destacando-se as publicações: "Vidas do Fora: habitantes do silêncio" (Editora da UFRGS, 2010) e "Estratégias biográficas: biografema com Barthes, Deleuze, Nietzsche e Henry Miller" (Sulina, 2011). Coordena o Dicionário Raciocinado das Licenciaturas (www.ufrgs.br/dicionariodaslicenciaturas), atualmente no IV tomo de publicação. Endereço institucional: Faculdade de Educação da UFRGS. Av Paulo Gama, s/n - Bairro Farroupilha. Telefone 33083426. Endereço eletrônico: bedin.costa@gmail.com

Recebido em: 25/07/2014

Aprovado em: 08/08/2014 